\title{
SOIL MOISTURE ANALYSIS OF LALITPUR DISTRICT UTTAR PRADESH INDIA USING LANDSAT AND SENTINEL DATA
}

\author{
Sunil Kumar Yadav ${ }^{1, *}$, Pragati Singh ${ }^{1}$, Shiv Pal Singh Jadaun ${ }^{1}$, Narendra Kumar ${ }^{2}$, R. K. Upadhyay ${ }^{1}$ \\ Remote Sensing Applications Centre Uttar Pradesh, Lucknow India \\ ${ }^{1}$ (suni101080, singh22pragati, shivpalsingh.jadaun, rsacupard)@gmail.com \\ (rsacupnk@rediffmail.com)
}

KEYWORDS: AMSR-2, In-situ measurement, Landsat, LST, NDVI, NDWI, Sentinel, Soil moisture.

\begin{abstract}
:
Soil moisture is the available water content within the voids of soil particles. Remote sensing and GIS technique provide an advance \& better information to extract the soil moisture of Lalitpur district Uttar Pradesh. The Landsat-8 OLI+TIRS (Optical Level Imager +Thermal Infrared Sensor) data (2013-18) and Sentinel 2A \& 2B data (2015-18) was used to retrieve soil moisture content for the period 2013-2018. The optical and thermal bands were used to retrieve Land surface temperature (LST), NDVI and NDWI of Lalitpur district for the different years. Using land surface temperature encompasses with NDVI and NDWI the moisture content of the soil was estimated for the study area.Using Advance Microwave Scanning Radiometer-2, (2013-18) (AMSR-2) data and measurement of soil moisture through in-situ (Field) soil samples collections for soil moisture estimation was used to check the accuracy of the output resulted from Landsat and Sentinel data. This study results that; the output obtained from Landsat- 8 in comparison to Sentinel data provide an accurate and better information of soil moisture at a high resolution.
\end{abstract}

\section{INTRODUCTION}

An agriculture point of view the soil moisture plays an important role for crop growth. The upper layer of the earth's surface most valuable for runoff, infiltration and evaporation. Remote sensing (RS) provide large scale specialization and monitoring of soil moisture near to the land surface $(0-5 \mathrm{~cm})$. The soil optical reflection, thermal emission and microwave backscatter are much correlated with soil moisture content. AMSR-2 satellite observation is not well favourable for small -scale applications due to their instinctively coarse resolution. The "trapezoid or triangle" models are used in remote sensing of surface soil moisture based on coupled thermal (i.e., land surface temperature) and optical RS observation.

There are two trapezoid models were used by Sadeghi et al. to retrieve the soil moisture. First is Thermal Optical Trapezoid Model and second is Optical Trapezoid Model. TOTRAM model needs thermal and optical bands whereas OPTRAM; optical. Using both the model soil moisture content was retrieve for the Lalitpur district Uttar Pradesh.

Landsat 8 has optical and thermal both the bands. The Landsat 8 data was used for both the OPTRAM and TOTRAM models. Whereas the sentinel data has only optical band so the TOTRAM was performed using the thermal band of Land sat and OPTRAM by Sentinel itself.

\section{STUDY AREA \& DATA SETS USED}

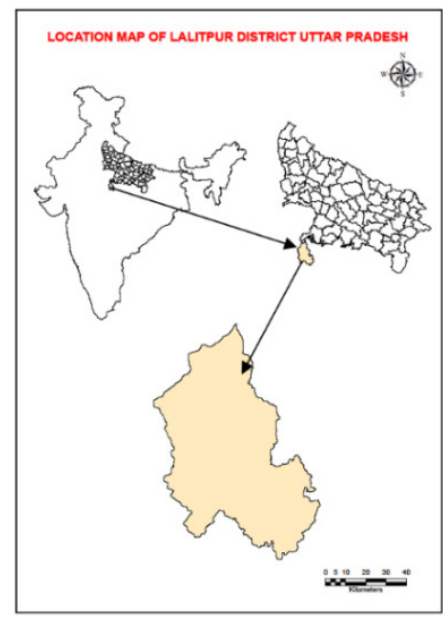

Figure 1: Location Map of Study area

Lalitpur is one of the district of Bundelkhand region of Uttar Pradesh province of India. It lies between Latitude $24^{0} 11^{\prime} \mathrm{N}$ to $24^{\circ} 14^{\prime} \mathrm{N}$ and Longitude be $78^{\circ} 8^{\prime} \mathrm{E}$ and $79^{\circ} 0^{\prime} \mathrm{E}$. what's more, is limited by locale Jhansi in the north, Sagar and Tikamgarh districts of Madhya Pradesh state in the east and Guna district of Madhya Pradesh isolated by stream Betwa in the west. The district encompasses around 5,039sq km area (Figure: 1 ).

The data sets which were used in this study are given in Table no. 1 


\begin{tabular}{|c|c|c|c|c|c|c|}
\hline Data & $\begin{array}{c}\text { Acquisition } \\
\text { Year }\end{array}$ & Source & $\begin{array}{c}\text { Scale/ } \\
\text { Spatial } \\
\text { Resolution }\end{array}$ & $\begin{array}{c}\text { Radiometric } \\
\text { Resolution }\end{array}$ & Bands & Purpose \\
\hline AMSR2 & $2012-2017$ & JAXA & $\begin{array}{c}1: 1,000,00 \\
0 / 10 \mathrm{~km}\end{array}$ & 16 Bits & L & $\begin{array}{c}\text { Checking } \\
\text { soil } \\
\text { moisture } \\
\text { accuracy }\end{array}$ \\
\hline $\begin{array}{c}\text { SENTINEL } \\
\text { 2A,B }\end{array}$ & $2015-2018$ & USGS & $10 \mathrm{~m}$ & 12 Bits & 12 & $\begin{array}{c}\text { soil } \\
\text { moisture } \\
\text { retrieval }\end{array}$ \\
\hline $\begin{array}{c}\text { Land sat 8 } \\
\text { (OLI+TIRS) }\end{array}$ & $2012-2018$ & USGS & $\begin{array}{c}30 \mathrm{M}(\mathrm{visib} \\
\text { SWIR }) \\
100 \mathrm{~m} \\
\text { (thermal) } 1 \\
5 \mathrm{~m}(\mathrm{pan})\end{array}$ & 11 Bit & 11 & $\begin{array}{l}\text { moisture } \\
\text { retrieval }\end{array}$ \\
\hline
\end{tabular}

Table 1: Description of datasets used

\section{METHODOLOGY}

\subsection{Normalized Difference Water Stress Index Estimation:}

Landsat 8 bands 6 and 5 as; shortwave infra-red (SWIR) and near-infra red (NIR) bands were used to generate NDWI with the following formula:

$\mathrm{NDWI}=($ Band $6(\mathrm{SWIR})-$ Band $5(\mathrm{NIR})) /($ Band $6(\mathrm{SWIR})+$ Band 5(NIR))

\subsection{Normalized Difference Vegetation Index}

Landsat 8 bands 6 and 5 as; red (R) and near-infra red (NIR) bands were used to generate NDVI with the following formula:

$\mathrm{NDVI}=($ Band $5(\mathrm{NIR})-$ Band $4(\mathrm{R})) /($ Band $5(\mathrm{NIR})+$ Band 4 (R))

\subsection{Land Surface Temperature Estimation (LST) Algorithm}

1 STEP - TOA \{Top of atmospheric spectral radiance\}

$$
\mathrm{L}_{\kappa}=\mathrm{ML}+\mathrm{Qcal}+\mathrm{AL}-\mathrm{Oi}
$$

Where,

$\mathrm{L}_{\Lambda}=$ Spectral radiance

$\mathrm{ML}_{\mathrm{L}}=$ Band specific (here band 10) multiplicative rescaling factor $=0.000334$

Qcal $=$ Band 10 image

$\mathrm{A}_{\mathrm{L}}=$ Band specific additive rescaling factor $=0.100000$

$\mathrm{Oi}=$ Correction for band 10

2 STEP - Conversion of digital number nos. into reflection

3 STEP - Conversion of spectral radiance to brightness temperature (BT).The radiance values are next converted to brightness images using thermal constants given in metadata file. The conversion formula used is as follows;

$$
\mathrm{BT}=K 2 \ln [(K 1 / L \lambda)+1]-273.15
$$

$\mathrm{T}=$ Satellite brightness temperature in Kelvin $L \lambda=$ Spectral radiance.

$\mathrm{K}_{1}=$ Band 10 thermal coefficient derived from metadata file. $\mathrm{K}_{2}=$ Band 10 thermal coefficient derived from metadata file. So, brightness temperature calculation equation is as follows;

\section{$\mathrm{T}=1321.0789 /\{\operatorname{In}(774.8853 / \mathrm{BAND} 10)+1\}-273.15$}

4 STEP-LAND SURFACE EMISSIVITY: The ability of a surface to emit the absorbed radiation is called emissivity of material. It is an important parameter determining the surface temperature of a material. Emissivity calculation is carried out through various methods, but for this study following method is applied,

$$
\mathrm{LSE}=\mu_{\mathrm{V}} * \mathrm{P}_{\mathrm{V}}+\mu_{\mathrm{S}} *\left(1-\mathrm{P}_{\mathrm{V}}\right)
$$

$\mu_{\mathrm{V}}=$ emissivity of vegetation at band $10(0.986)$.

$\mu_{\mathrm{S}}=$ emissivity of soil at band $10(0.914)$.

$\mathrm{P}_{\mathrm{V}}=$ proportion of vegetation.

5 STEP- LAND SURFACE TEMPERATURE CALCULATION: Land surface temperature is radiative surface temperature of land surface depending on vegetation cover and soil moisture. In present work for calculation of LST single channel algorithm has been utilised using band 10 of Landsat 8 TIRS .The equation is given below

$$
\mathrm{LST}=\mathrm{BT} /\{1+[(\lambda \mathrm{BT} / \mathrm{p}) \ln (\mathrm{LSE})\}
$$

$\mathrm{BT}=$ Brightness temperature.

LSE $=$ Land surface emissivity.

$\mathrm{p}=\mathrm{h} * \mathrm{c} / \mathrm{s}=14380 \mathrm{mK}$

$\mathrm{H}=$ plank's constant $\left(6.626^{*} 10^{-34} \mathrm{Js}\right)$

$\mathrm{S}=$ Boltzmann constant $\left(1.38 * 10^{-23} \mathrm{~J} / \mathrm{K}\right)$

$\mathrm{C}=$ Velocity of light $\left(2.998 * 10^{8} \mathrm{~m} / \mathrm{s}\right)$

Hence the equation used is as follows

$\mathrm{LST}=\mathrm{BT}($ Band 10$) /\{1+[(10.895 * \mathrm{BT}$

(Band10)/14380)* $\ln (\mathrm{LSE})\}$

$\mathrm{BT}(\mathrm{BAND} 10)=$ Brightness temperature of band 10 TIRS

LSE $=$ Land surface emissivity

After calculation of LST, LST for wheat area is estimated using wheat mask area.

\subsection{The traditional Thermal-Optical Trapezoid Model (TOTRAM)}

The conventional trapezoid model, TOTRAM, depends on the pixel conveyance inside the LST-VI space. The most widely recognized vegetation index used in TOTRAM is the Normalized Difference Vegetation Index (NDVI). A backwards direct connection between surface soil moisture $(\theta)$ and LST is then accepted:

$\mathrm{W}=\theta-\theta_{\mathrm{d}} / \theta_{\mathrm{w}}-\theta_{\mathrm{d}}$

$=\mathrm{LST}_{\mathrm{d}}-\mathrm{LST} / \mathrm{LST}_{\mathrm{d}}-\mathrm{LST}_{\mathrm{w}}$ 
Where is the soil moisture content standardized by the nearby least dry soil moisture content, $\theta \mathrm{d}$, and the neighbourhood maximum wet soil moisture content, $\theta \mathrm{w}$. The LSTd and LSTw terms are the LSTs of the dry and wet soil, respectively, where LSTd and LSTw are acquired from the LST-NDVI trapezoid for an explicit area (satellite scene). The upper (dry) and lower (wet) edges of the trapezoid are utilized to tackle for LSTd and LSTw at any given NDVI (i.e., partial vegetation cover):

$$
\begin{aligned}
& \operatorname{LST}_{\mathrm{d}}=\mathrm{i}_{\mathrm{d}}+_{\mathrm{sd}} \mathrm{NDVI} \\
& \mathrm{LST}_{\mathrm{w}}=\mathrm{i}_{\mathrm{w}}+{ }_{\mathrm{sw}} \mathrm{NDVI}
\end{aligned}
$$

CombiningEqs. (2), (3) and (4), the soil moisture for each pixel can be estimated as a function of LST and NDVI:

$\mathrm{W}=\mathrm{i}_{\mathrm{d}}+{ }_{\mathrm{sd}} \mathrm{NDVI}-\mathrm{LST} / \mathrm{i}_{\mathrm{d}}-\mathrm{i}_{\mathrm{w}}+(\mathrm{sd}-\mathrm{sw}) \mathrm{NDVI}$

\subsection{Optical Trapezoid Model (OPTRAM)}

The newtrapezoidmodel, OPTRAM, depends on the possibility of replacingLST in TOTRAM with a measure for soilmoisture in the optical space. In view of the Kubelka and Munk (1931) twotransition radiative exchange show, Sadeghi et al. (2015) built up a physical model displaying a straight connection between surface moisture substance and SWIR changed reflectance:

$$
\begin{aligned}
\mathrm{W} & =\theta-\theta_{\mathrm{d}} / \theta_{\mathrm{w}}-\theta_{\mathrm{d}} \\
& =\mathrm{STR}-\mathrm{STR}_{\mathrm{d}} / \mathrm{STR}_{\mathrm{w}}-\mathrm{STR}_{\mathrm{d}}
\end{aligned}
$$

Where:

STR is the SWIR transformed reflectance and STRd and STRware the STR at $\theta \mathrm{d}$ and $\theta \mathrm{w}$, respectively. The STR is related to SWIR reflectance, RSWIR, as follows:

$\mathrm{STR}=1-{ }_{\mathrm{R}} \mathrm{SWIR} / 2{ }_{\mathrm{R}} \mathrm{SWIR}$

The recently inferred Eq. (6) has been tried for exposed soils for two SWIR groups (i.e., $1650 \mathrm{~nm}$ comparing to band 6 of Landsat 8 , and $2210 \mathrm{~nm}$ corresponding to band 7 of Landsat 8), and it has been shown that the model is exceedingly exact, particularly at $2210 \mathrm{~nm}$. Eq. (6) was likewise determined for vegetated soils moisture on the Kubelka and Munk radiative exchange model and holds for any fragmentary vegetation cover (i.e., any NDVI). An extra presumption required for this determination is the straight connection among soil-and vegetation-water substance. For vegetated soils, $\theta$ in Eq. (6) is thought to be associated to root zone soil moisture through the vegetation reaction to soil moisture shortage in the root zone. This suspicion complies with past examinations (Wang et al., 2007; Crow et al., 2008; Liu et al., 2012; Schnur et al.,2010; Peng et al., 2014; Santos et al., 2014) that have connected remotelysensed vegetation lists to evaluate plant energy and relate it to root zone soil moisture. The soil moisture status impacts the vegetation water status and along these lines changes the unearthly attributes of the vegetation (Santos et al., 2014). The degree of the root zone changes relying upon plant type and development organize. For instance, for espresso trees, Santoset al. (2014) found the most elevated connection between's RS-based vegetation records and soil moisture to be at a profundity of $60 \mathrm{~cm}$. In view of the presumption of a direct connection among soil-and vegetation-water substance, we expect that the STR-NDVI space frames a trapezoid also. In this manner, the parameters of Eq. (6) can be acquired for an explicit area (e.g., satellite scene) from the dry and wet edges of the optical trapezoid, portrayed in Fig. :

$\mathrm{STR}_{\mathrm{d}}=\mathrm{i}_{\mathrm{d}}+_{\mathrm{sd}} \mathrm{NDVI}$

$\mathrm{STR}_{\mathrm{w}}=\mathrm{i}_{\mathrm{w}}+{ }_{\mathrm{sw}} \mathrm{NDVI}$

Combining Eqs. (6), (8) and (9), the soil moisture for each pixel can be estimated as a function of STR and NDVI:

$\mathrm{W}=\mathrm{i}_{\mathrm{d}}+{ }_{\mathrm{sd}} \mathrm{NDVI}-\mathrm{STR} / \mathrm{i}_{\mathrm{d}}-\mathrm{i}_{\mathrm{w}}+(\mathrm{sd}-\mathrm{sw}) \mathrm{NDVI}$

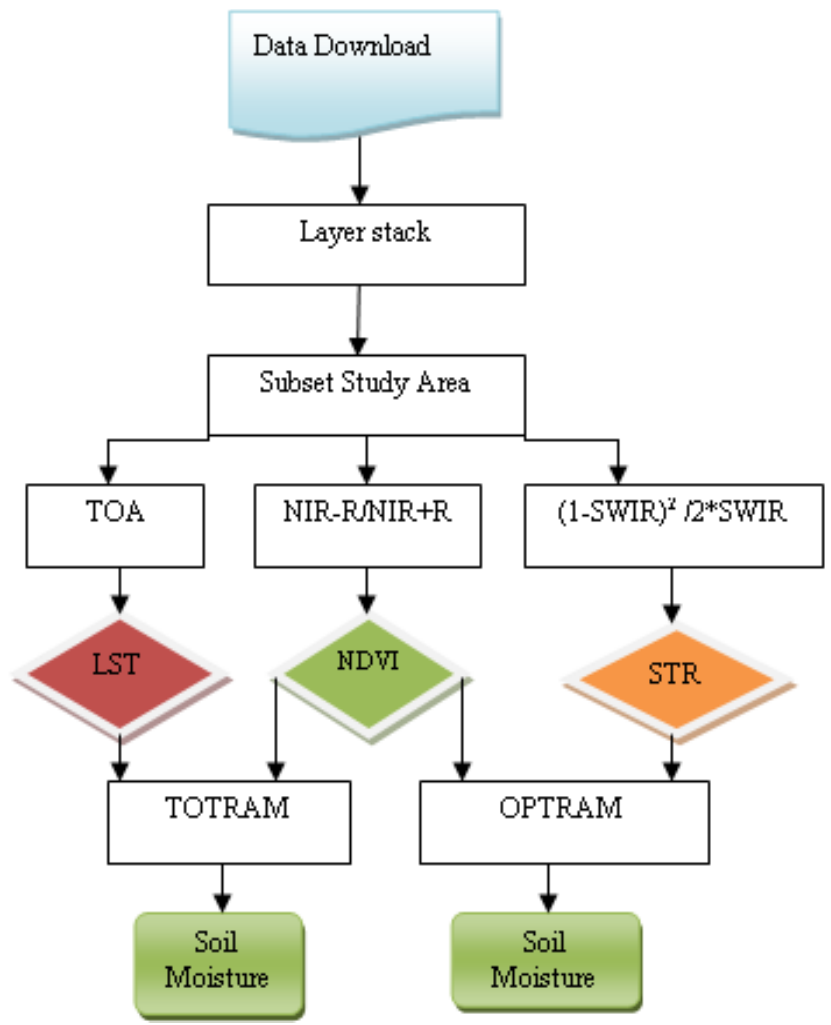

Figure 2: Methodology flow chart
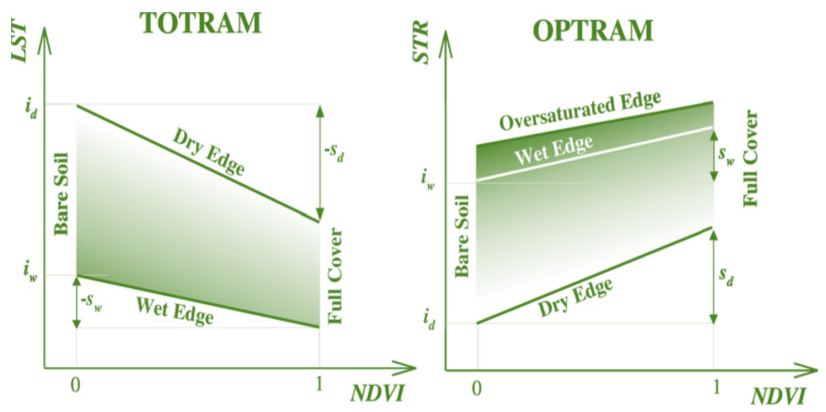

Figure 3: Sketch of OPTRAM and TOTRAM 


\section{RESULT \& DISCUSSION}

The soil moisture estimated from the Landsat 8 OLI+TIRS data was estimated for the Lalitpur district of Uttar Pradesh. The optical trapezoid model and thermal trapezoid model for the study area was used to retrieve the soil moisture of the study area. The both the technique provide the moisture content of the study area from 0 to 100 percent but the result obtained from thermal trapezoid model was more accurate than the result obtained from optical trapezoid model. Sadeghi et al. used optical and thermal trapezoid model to retrieve the soil moisture but the soil moisture resulted from optical trapezoid model was over estimated whereas the accuracy of result obtained from thermal trapezoid model was near about the soil moisture estimated from the field samples.

The accuracy assessment of the result was done by the soil samples collected from the field (Table no. 2) and weighed before and after 72 hours after oven dry. As well as AMSR 2 soil moisture data was also used to check the accuracy of the result obtained from the thermal and optical model. While checking the accuracy, it was found out that result obtained from the thermal trapezoid model perform on Landsat 8 data was more accurate and the optical model over estimates the soil moisture content of the field. The total accuracy of the result obtained from TOTRAM by Landsat 8 was $\pm 10 \%$. Whereas when the TOTRAM perform on the thermal band of Landsat 8 and optical bands of Sentinel 2, the result also obtained from 0 to $100 \%$. But acquisition date and radiometry of both the satellite data was different due to which the soil moisture resulted by the combined Landsat 8 and Sentinel data was not much accurate as the TOTRAM perform on Landsat 8 OLI+TIRS itself. The overall accuracy is decreases for Landsat 8 , it was $\pm 10 \%$ and $\pm 20 \%$ by sentinel.

\begin{tabular}{|c|c|c|c|c|c|c|c|}
\hline $\begin{array}{c}\text { SAMPLE } \\
\text { NO. }\end{array}$ & DEPTH & LATITUDE & LONGITUDE & $\begin{array}{c}\text { SOIL } \\
\text { WEIGHT } \\
\text { BEFORE } \\
\text { (gm) }\end{array}$ & $\begin{array}{c}\text { SOIL } \\
\text { WEIGHT } \\
\text { AFTER } \\
\text { (gm) }\end{array}$ & $\begin{array}{c}\text { WEIGHT } \\
\text { OF } \\
\text { WATER } \\
\text { (gm) }\end{array}$ & $\begin{array}{c}\text { Moisture } \\
\text { (\%) }\end{array}$ \\
\hline $\mathbf{1}$ & $5 \mathrm{CM}$ & 24.6384 & 78.47072 & 325.17 & 277.09 & 48.08 & 17.35 \\
\hline $\mathbf{2}$ & $5 \mathrm{CM}$ & 24.63841 & 78.47093 & 246.17 & 218.9 & 27.27 & 12.45 \\
\hline $\mathbf{3}$ & $5 \mathrm{CM}$ & 24.63839 & 78.4716 & 273.85 & 260.5 & $13 . .35$ & 5.12 \\
\hline $\mathbf{4}$ & $30 \mathrm{CM}$ & 24.6384 & 78.47072 & 294.43 & 275.6 & 18.83 & 6.84 \\
\hline $\mathbf{5}$ & $30 \mathrm{CM}$ & 24.63839 & 78.4716 & 334.875 & 288.1 & 46.775 & 16.24 \\
\hline $\mathbf{6}$ & $5 \mathrm{CM}$ & 24.52866 & 78.60313 & 288.1 & 266.9 & 21.2 & 7.95 \\
\hline $\mathbf{7}$ & $5 \mathrm{CM}$ & 24.528 & 78.60344 & 261.9 & 234.4 & 27.5 & 11.74 \\
\hline $\mathbf{8}$ & $30 \mathrm{CM}$ & 24.52866 & 78.60313 & 289.65 & 237.9 & 51.75 & 21.76 \\
\hline $\mathbf{9}$ & $30 \mathrm{CM}$ & 24.528 & 78.60344 & 290.34 & 261.06 & 29.28 & 11.22 \\
\hline $\mathbf{1 0}$ & $5 \mathrm{CM}$ & 24.48594 & 78.61482 & 254.765 & 223.2 & 31.565 & 14.15 \\
\hline $\mathbf{1 1}$ & $30 \mathrm{CM}$ & 24.48594 & 78.61482 & 306.815 & 270.4 & 36.415 & 13.47 \\
\hline $\mathbf{1 2}$ & $5 \mathrm{CM}$ & 24.35936 & 78.794 & 327.97 & 285.87 & 42.1 & 14.73 \\
\hline $\mathbf{1 3}$ & $5 \mathrm{CM}$ & 24.36037 & 78.7951 & 328 & 294.5 & 33.5 & 11.38 \\
\hline $\mathbf{1 4}$ & $30 \mathrm{CM}$ & 24.35936 & 78.794 & 363.225 & 304.32 & 58.905 & 19.36 \\
\hline $\mathbf{1 5}$ & $30 \mathrm{CM}$ & 24.36037 & 78.7951 & 396.105 & 295.86 & 100.245 & 33.88 \\
\hline $\mathbf{1 6}$ & $5 \mathrm{~cm}$ & 24.48945 & 78.74048 & 354.97 & 272.56 & 82.41 & 30.24 \\
\hline $\mathbf{1 7}$ & $30 \mathrm{~cm}$ & 24.48945 & 78.74048 & 371.975 & 290.44 & 81.535 & 28.08 \\
\hline $\mathbf{1 8}$ & $5 \mathrm{~cm}$ & 24.65191 & 78.73713 & 265.385 & 227.53 & 37.855 & 13.63 \\
\hline $\mathbf{1 9}$ & $5 \mathrm{~cm}$ & 24.65169 & 78.73058 & 288.09 & 253.06 & 35.03 & 13.85 \\
\hline $\mathbf{2 0}$ & $30 \mathrm{~cm}$ & 24.65191 & 78.73713 & 381.335 & 315.47 & 65.865 & 20.87 \\
\hline $\mathbf{2 1}$ & $30 \mathrm{~cm}$ & 24.65169 & 78.73058 & 352.39 & 296.26 & 56.13 & 18.95 \\
\hline $\mathbf{2 2}$ & $5 \mathrm{~cm}$ & 24.81526 & 78.46301 & 264.65 & 249.42 & 15.23 & 6.11 \\
\hline $\mathbf{2 3}$ & $5 \mathrm{~cm}$ & 78.81527 & 78.46268 & 255.22 & 242.43 & 12.79 & 5.28 \\
\hline $\mathbf{2 4}$ & $5 \mathrm{~cm}$ & 24.81609 & 78.46274 & 259.525 & 251.89 & 7.635 & 3.03 \\
\hline $\mathbf{2 5}$ & $30 \mathrm{~cm}$ & 24.81526 & 78.46301 & 258.885 & 236.25 & 22.635 & 9.59 \\
\hline $\mathbf{2 6}$ & $30 \mathrm{~cm}$ & 78.81527 & 78.46268 & 254.57 & 231.49 & 23.08 & 9.98 \\
\hline $\mathbf{2 7}$ & $5 \mathrm{~cm}$ & 25.02657 & 78.42689 & 320.16 & 275.18 & 44.98 & 16.34 \\
\hline $\mathbf{2 8}$ & $30 \mathrm{~cm}$ & 25.02657 & 78.42689 & 282.905 & 247.52 & 35.385 & 14.3 \\
\hline & & & & & & & \\
\hline
\end{tabular}

Table 2: Collected soil samples and measured soil moisture
The following table no 2 represents the collected soil samples from different locations of Lalitpur district of Uttar Pradeh at different depth to check the accuracy resulted from the output comes from optical and thermal trapezoid models.

The following map given from the figure no 4 (i) to (xxxx) represent the soil moisture of Lalitpur district from 2013 to 2018 retrieve by TOTRAM using Landsat 8 ;

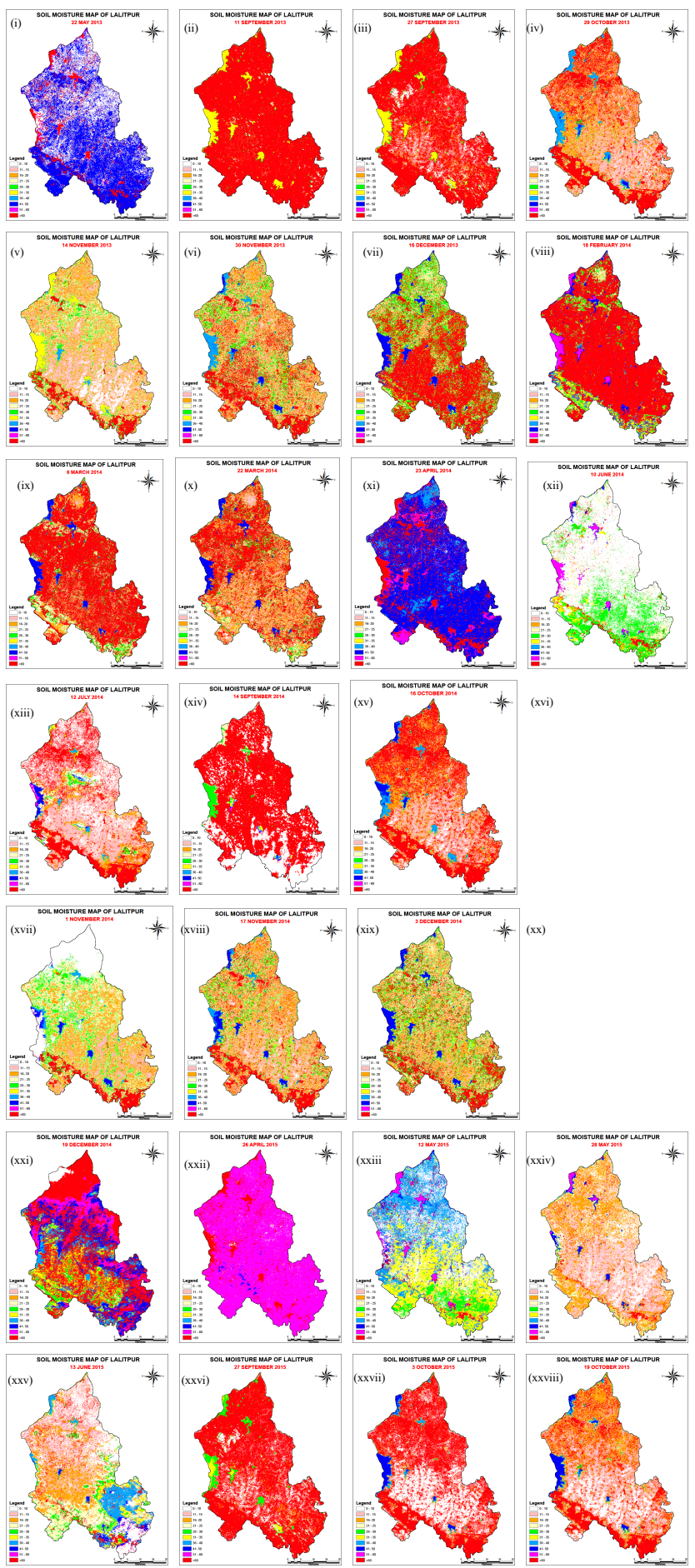




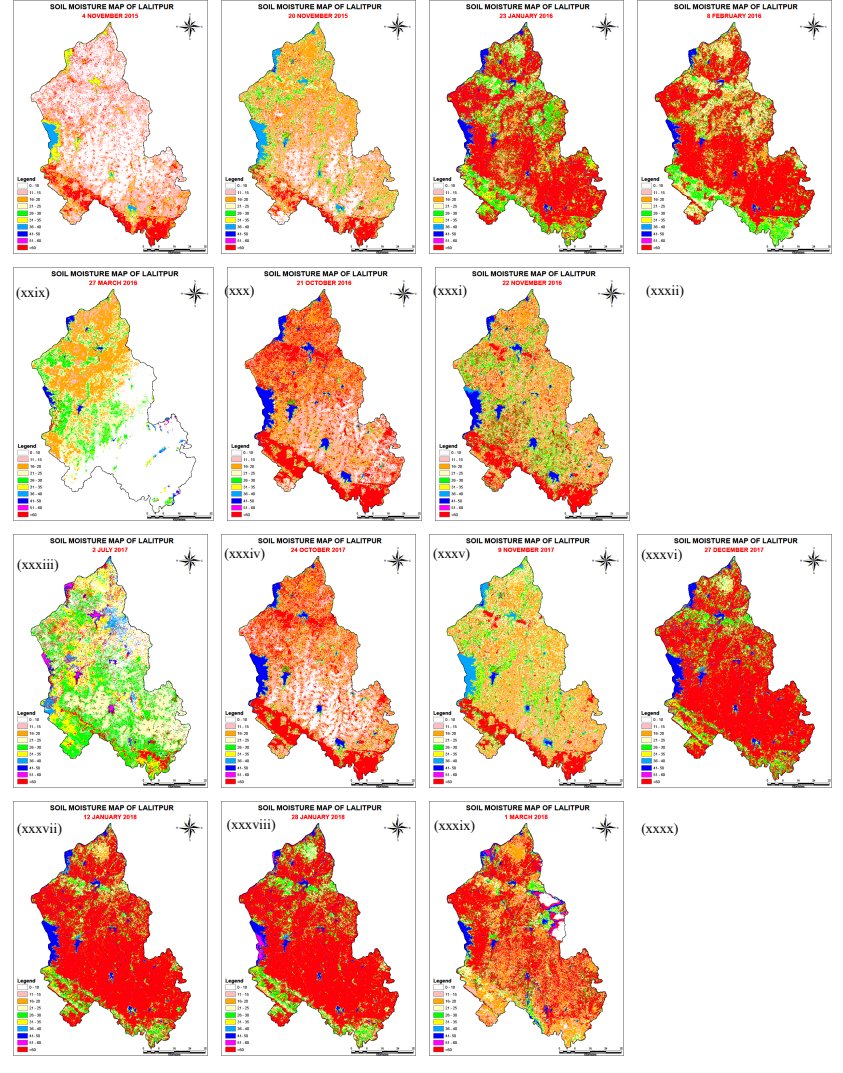

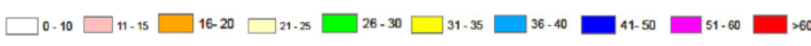

Figure 4 (i) to (xxxx): Soil moisture map of Lalitpur 2013-2018

By the above maps given from figure no 4 (i) to figure no 4 $(\mathrm{xxxx})$, it can be seen that, the soil moisture content for the study area was categorized in 10 classes as; 0 to 10 to $>60 \%$ because at $60 \%$ of moisture level the soils become over saturated.

By the above map it can be illustrate that the moisture content in the soil is properly classified except the heavy vegetation areas, haze/cloudy conditions and over the water bodies because the optical and thermal data has the low penetration ability due to its shorter wavelength compare to microwave, which can penetrate through cloud, haze vegetation etc.

The maps given in the figure no 4 can illustrate that during the crop maturing stage when fully covered with vegetation, the moisture content was higher because Landsat data can not penetrate through the vegetation. Like this forest covered areas and the foggy climatic situation the moisture content was over estimated. And over the water bodies the moisture content was wrongly estimated, whereas over the low vegetative areas and land surface the moisture content was accurately estimated.

The soil moisture find out by TOTRAM from January to December, it was seen that, the moisture content accurately estimated for all the months of the year except the mid of February to first half of march and during September. This was the crop maturing stage when field is fully or densely covered with vegetation due to which the optical and thermal bands can not provide right information because of they can not penetrate through heavy vegetation. Whereas the TOTRAM model was limited by the cloudy/hazy climatic conditions as well as over the water bodies. Other than these limitations the soil moisture resulted from Landsat 8 TOTRAM provide a high resolution and better result for the surface soil moisture.

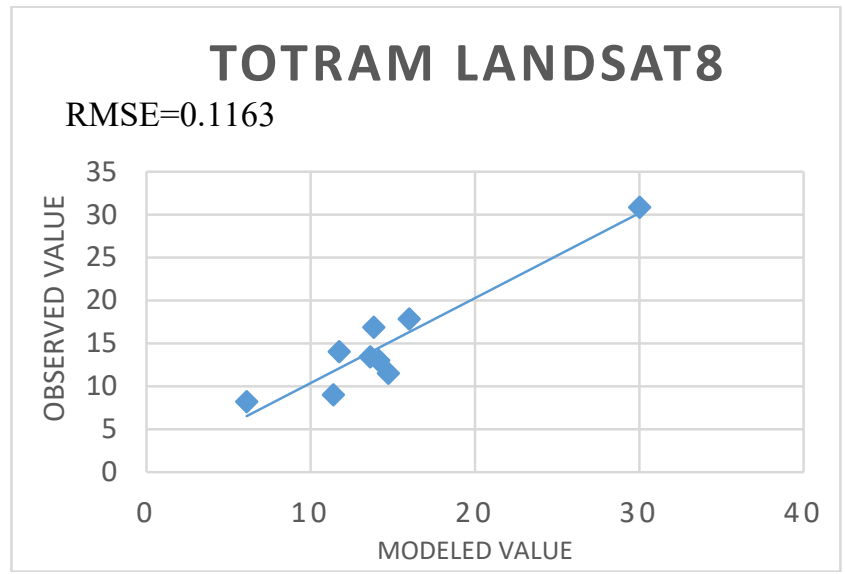

Figure 5: TOTRAM soil moisture estimation compared with insitu measurement

This model was also used to obtain the soil moisture for other districts including Lalitpur of the Uttar Pradesh (Pilibhit, Lucknow, Barabanki, Amethi, Raebareli and Sultanpur) to check the accuracy of the result and it was compared with the observed (more than 10 samples for each districts) soil moisture by ground sampling. While comparing both the result by observed and modelled soil moisture the accuracy achieved $+10 \%$ and the RMSE for observed and modelled values was 0.1163 as given in the figure no 5 . So that by this study it resulted that the TOTRAM model for soil moisture analysis at high resolution gives a better result.

\section{CONCLUSION}

By this study we find out that, the soil moisture analysis done by OPTRAM and TOTRAM both the model using Sentinel 2 and Landsat 8 OLI+TIRS data, where OPTRAM by both the satellite data did not performed better whereas TOTRAM by Landsat 8 OLI+TIRS results better than Sentinel. And the limitations of the soil moisture resulted by Landsat 8 TOTRAM is cloudy/hazy weather, dense vegetation, forest cover and water bodies.

\section{ACKNOWLEDGMENT}

The authors are thankful to the Director of RSAC UP, head School of Geoinformatics and the staff of Agriculture Resources Division of RSAC Uttar Pradesh.

\section{REFERENCES}

Barrett, B. and Petropoulos, G.P., 2013. Satellite remote sensing of surface soil moisture. Remote sensing of energy fluxes and soil moisture content, 85 .

Barrett, B.W., Dwyer, E. and Whelan, P., 2009. Soil moisture retrieval from active spaceborne microwave observations: An 
evaluation of current techniques. Remote sensing, 1(3), pp.210242.

Chauhan, N.S., Miller, S. and Ardanuy, P., 2003. Spaceborne soil moisture estimation at high resolution: a microwave-optical/IR synergistic approach. International Journal of Remote Sensing, 24(22), pp.4599-4622.

Cui, C., Xu, J., Zeng, J., Chen, K.S., Bai, X., Lu, H., Chen, Q. and Zhao, T., 2018. Soil moisture mapping from satellites: An intercomparison of SMAP, SMOS, FY3B, AMSR2, and ESA CCI over two dense network regions at different spatial scales. Remote Sensing, 10(1), p.33.

Engman, E.T. and Chauhan, N., 1995. Status of microwave soil moisture measurements with remote sensing. Remote Sensing of Environment, 51(1), pp.189-198.

Fontanet, M., Fernàndez-Garcia, D. and Ferrer, F., 2018. The value of satellite remote sensing soil moisture data and the DISPATCH algorithm in irrigation fields. Hydrology and Earth System Sciences, 22(11), pp.5889-5900.

Grote, K., Hubbard, S. and Rubin, Y., 2003. Field-scale estimation of volumetric water content using ground-penetrating radar ground wave techniques. Water resources research, 39(11).

Jackson, T.J., Le Vine, D.M., Swift, C.T., Schmugge, T.J. and Schiebe, F.R., 1995. Large area mapping of soil moisture using the ESTAR passive microwave radiometer in Washita'92. Remote sensing of Environment, 54(1), pp.27-37.

Jackson, T.J., 1993. III. Measuring surface soil moisture using passive microwave remote sensing. Hydrological processes, 7(2), pp.139-152.

Kerr, Y.H., Waldteufel, P., Wigneron, J.P., Martinuzzi, J.A.M.J., Font, J. and Berger, M., 2001. Soil moisture retrieval from space: The Soil Moisture and Ocean Salinity SMOS) mission. IEEE transactions on Geoscience and remote sensing, 39(8), pp.17291735.

O'neill, P.E., Chauhan, N.S. and Jackson, T.J., 1996. Use of active and passive microwave remote sensing for soil moisture estimation through corn. International Journal of Remote Sensing, 17(10), pp.1851-1865.

Sadeghi, M., Babaeian, E., Tuller, M. and Jones, S.B., 2017. The optical trapezoid model: A novel approach to remote sensing of soil moisture applied to Sentinel-2 and Landsat-8 observations. Remote sensing of environment, 198, pp.52-68.

Sonika Sharma 2006. Soil moisture estimation using active and passive microwave remote sensing techniues.

Wang, L. and Qu, J.J., 2009. Satellite remote sensing applications for surface soil moisture monitoring: A review. Frontiers of Earth Science in China, 3(2), pp.237-247.

Younis, S.M.Z. and Iqbal, J., 2015. Estimation of soil moisture using multispectral and FTIR techniques. The Egyptian Journal of Remote Sensing and Space Science, 18(2), pp.151-161. 